\title{
RESEARCH
}

Open Access

\section{Effectiveness and safety of opicapone in Parkinson's disease patients with motor fluctuations: the OPTIPARK open-label study}

Heinz Reichmann ${ }^{1}$, Andrew Lees², José-Francisco Rocha ${ }^{3}$, Diogo Magalhães ${ }^{3,5}$, Patrício Soares-da-Silva ${ }^{4,5,6^{*}}$ (D) and the OPTIPARK investigators

\begin{abstract}
Background: The efficacy and safety of opicapone, a once-daily catechol-O-methyltransferase inhibitor, have been established in two large randomized, placebo-controlled, multinational pivotal trials. Still, clinical evidence from routine practice is needed to complement the data from the pivotal trials.

Methods: OPTIPARK (NCT02847442) was a prospective, open-label, single-arm trial conducted in Germany and the UK under clinical practice conditions. Patients with Parkinson's disease and motor fluctuations were treated with opicapone $50 \mathrm{mg}$ for 3 (Germany) or 6 (UK) months in addition to their current levodopa and other antiparkinsonian treatments. The primary endpoint was the Clinician's Global Impression of Change (CGI-C) after 3 months. Secondary assessments included Patient Global Impressions of Change (PGI-C), the Unified Parkinson's Disease Rating Scale (UPDRS), Parkinson's Disease Questionnaire (PDQ-8), and the Non-Motor Symptoms Scale (NMSS). Safety assessments included evaluation of treatment-emergent adverse events (TEAEs) and serious adverse events (SAEs).

Results: Of the 506 patients enrolled, 495 (97.8\%) took at least one dose of opicapone. Of these, 393 (79.4\%) patients completed 3 months of treatment. Overall, 71.3 and $76.9 \%$ of patients experienced any improvement on CGI-C and PGI-C after 3 months, respectively (full analysis set). At 6 months, for UK subgroup only $(n=95), 85.3 \%$ of patients were judged by investigators as improved since commencing treatment. UPDRS scores at 3 months showed statistically significant improvements in activities of daily living during OFF (mean \pm SD change from baseline: $-3.0 \pm 4.6, p<$ $0.0001)$ and motor scores during ON $(-4.6 \pm 8.1, p<0.0001)$. The mean \pm SD improvements of $-3.4 \pm 12.8$ points for PDQ-8 and $-6.8 \pm 19.7$ points for NMSS were statistically significant versus baseline (both $p<0.0001$ ). Most of TEAEs (94.8\% of events) were of mild or moderate intensity. TEAEs considered to be at least possibly related to opicapone were reported for $45.1 \%$ of patients, with dyskinesia (11.5\%) and dry mouth (6.5\%) being the most frequently reported. Serious TEAEs considered at least possibly related to opicapone were reported for $1.4 \%$ of patients.
\end{abstract}

Conclusions: Opicapone $50 \mathrm{mg}$ was effective and generally well-tolerated in PD patients with motor fluctuations treated in clinical practice.

Trial registration: Registered in July 2016 at clinicaltrials.gov (NCT02847442).

Keywords: Levodopa, Motor fluctuations, Open-label, Opicapone, Parkinson's disease

\footnotetext{
* Correspondence: psoares.silva@bial.com

${ }^{4}$ Research and Development Department, BIAL - Portela \& CA S.A, da

Siderurgia Nacional, 4745-457 S Mamede do Coronado, Portugal

${ }^{5}$ Department of Pharmacology and Therapeutics, Faculty of Medicine,

University Porto, Porto, Portugal

Full list of author information is available at the end of the article
}

(c) The Author(s). 2020 Open Access This article is distributed under the terms of the Creative Commons Attribution 4.0 International License (http://creativecommons.org/licenses/by/4.0/), which permits unrestricted use, distribution, and reproduction in any medium, provided you give appropriate credit to the original author(s) and the source, provide a link to the Creative Commons license, and indicate if changes were made. The Creative Commons Public Domain Dedication waiver (http://creativecommons.org/publicdomain/zero/1.0/) applies to the data made available in this article, unless otherwise stated. 


\section{Introduction}

The success of levodopa used together with other antiparkinsonian drug classes means that most patients living with Parkinson's disease (PD) enjoy a good quality of life for many years $[1,2]$. Nevertheless, the long term therapeutic response is marred in many by the emergence of disabling fluctuations and dyskinesias $[3,4]$ that lead to a reduced quality of life and motor handicap [2, 5]. Wearing-off results from levodopa's short duration response which reflects the amino acid's short half-life ( 60-90 min) [6]. Over time, patients will experience more and more hours per day in a disabling OFF-state and some will develop intrusive and adventitious involuntary movements [7].

Current treatment guidelines consider adjunctive treatment with catechol-O-methyltransferase (COMT) inhibitors, dopamine agonists and monoamine oxidase type $\mathrm{B}$ (MAO-B) inhibitors, as efficacious to reduce OFF time in patients treated with levodopa/dopa decarboxylase inhibitor (DDCI) therapy [8-10]. In routine practice, many physicians will also consider various formulations of levodopa (e.g. controlled-release and extended-release preparations) as well as dosing manipulations to increase the dose and/ or dosing frequency of levodopa. COMT inhibitors have been an established first-line strategy to manage motor fluctuations for over 25 years [11-14], and are the only adjunct class to directly address the peak-trough variations in plasma levodopa levels that clinically manifest as wearing-off fluctuations [15]. The third generation COMT inhibitor - opicapone (Ongentys ${ }^{\ominus}$, BIAL-Portela \& $C^{\text {a }}$, S.A. Portugal) - has been approved in Europe since 2016 as adjunct therapy to preparations of levodopa/DDCI for end-of-dose motor fluctuations. Based on rational drug design, opicapone was specifically developed to reduce the risk of toxicity and improve peripheral tissue selectivity [16]. In one pharmacokinetic study, opicapone (50 mg once daily) significantly increased levodopa bioavailability compared with both placebo and entacapone (200 mg TID) by increasing substantially the trough plasma levels and each dose systemic exposure time (half-life) by at least $1 \mathrm{~h}$ [17]. Phase III studies have established that treatment with opicapone $50 \mathrm{mg}$ once daily reduces daily OFF-time, without significantly increasing ON-time with troublesome dyskinesia versus placebo, and most patients show an improvement in the Clinician's Global Impression of Change (CGI-C) $[18,19]$.

While placebo-controlled trials remain the gold standard in assessing response to a therapeutic intervention, alone they do not provide sufficient information of clinical effectiveness and safety. Many regulators and payers now encourage the supplementation of randomized controlled trials with other forms of evidence, such as 'realworld' studies [20,21]. The aim of this study was to evaluate the change in the patient's perception about his/her global PD condition (as assessed by CGI-C) after 3 months of routine treatment in clinical practice with once-daily opicapone $50 \mathrm{mg}$.

\section{Methods \\ Study conduct}

This was a prospective open-label, single-arm, multicenter trial evaluating opicapone $50 \mathrm{mg}$ effectiveness in levodopa-treated PD patients experiencing motor fluctuations. The study was conducted from November 2016 to July 2018 at 68 specialist neurology centers in Germany and the United Kingdom (UK). Institutional review boards at the participating sites approved the protocol and the trial was conducted in accordance with the Declaration of Helsinki and International Conference on Harmonization Good Clinical Practice Guidelines. All patients provided written informed consent; the study was registered at EudraCT (2016-002391-27) and clinicaltrials.gov (NCT02847442).

\section{Study population}

Men and women ( $\geq 30$ years) with idiopathic PD [22] were eligible if they reported symptoms of motor fluctuations as identified by at least one symptom on the 9-Symptom Wearing-off Questionnaire (WOQ-9) [23]. They also had to be Hoehn and Yahr stages I-IV (during ON) and treated with 3-7 daily doses of levodopa/DDCI. Key exclusion criteria were atypical parkinsonism, severe unpredictable OFF periods (investigator judgment) and severe hepatic impairment (Child-Pugh Class C). Patients previously or currently treated with tolcapone and/or opicapone were also excluded from the study, as were patients treated with MAO-A and MAO-B inhibitors other than those for the treatment of PD [i.e. selegiline $(\leq 10 \mathrm{mg} /$ day in oral formulation or $\leq 1.25 \mathrm{mg} /$ day in buccal formulation), rasagiline $(\leq 1 \mathrm{mg} /$ day $)$ or safinamide $(\leq 100 \mathrm{mg}$ / day)]. Patients treated with levodopa/DDCI/entacapone before trial entry were to discontinue entacapone at the baseline visit and switch to a levodopa/DDCI formulation. Likewise, separate entacapone was to be discontinued by the baseline visit at the latest.

\section{Study design}

Patients received opicapone $50 \mathrm{mg}$ capsules once-daily at bedtime, at least 1 hour before or after the last daily dose of levodopa/DDCI. The total duration of treatment was 6 months in UK sites and 3 months in German sites. The longer duration of study in the UK was to provide data for economic modelling which will be reported elsewhere. Investigators were free to adjust total daily levodopa/DDCI doses according to individual need after the baseline visit. At study end, patients could be prescribed with further opicapone treatment according to local standard practice. 
Endpoints were assessed at baseline, 1 month and 3 months or at any early discontinuation visit, and patients in the UK were also assessed at 6 months. Best efforts were made to have the same investigator/rater per patient throughout the study. The primary outcome was the CGI-C (7 point scale, from very much improved to very much worse), which assessed the patient's perception about his/her global PD condition after 3 months of treatment with opicapone $50 \mathrm{mg}$; the same rater assessed CGI-C throughout the study and before the patient made his/her own assessment. Secondary assessments included the Patient's Global Impression of Change (PGI-C), WOQ-9 assessments, the Unified Parkinson's Disease Rating Scale (UPDRS) sections I-IV [24], the Parkinson's Disease Questionnaire (PDQ-8) [25], the Non-motor Symptoms Scale (NMSS) [26] and change from baseline in total daily levodopa dose and dosing frequency. Treatment compliance was calculated based on the numbers of dispensed and returned opicapone capsules and treatment duration excluding interruptions to study medication.

Safety was assessed through reporting of treatment emergent adverse events (TEAEs) as well as vital signs and physical and neurological examinations. Prespecified subgroup analyses also evaluated change from baseline in levodopa total daily dose in patients who reported dopaminergic adverse events (i.e. dyskinesia, nausea, vomiting, orthostatic hypotension, any hallucination, illusion, delusion or disturbance in attention).

\section{Statistical analysis}

No sample size estimation was performed for this openlabel study. The safety population included all patients who received $\geq 1$ dose of opicapone. Effectiveness was assessed in the full analysis set which included all patients in the safety population who had $\geq 1$ CGI-C recorded post-baseline. Analyses were primarily descriptive; missing values for the primary outcome measure (CGI-C) at Visit 4 was imputed using the last observation carried forward method. For UPDRS II (at ON and OFF), UPDRS III (at ON), UPDRS II plus III (at ON), PDQ-8 and NMSS (including each domain) the means of changes from baseline were analyzed using Student's t-test.

In addition, subgroup analyses for the primary endpoint were performed by age (above vs. below the baseline mean age), baseline use of dopamine agonists and dopamine agonists plus MAO-B inhibitors (yes/no).

\section{Results}

Patient disposition and baseline characteristics

Five-hundred and six patients were enrolled at 68 centers across Germany and the UK. Of these, 495 (97.8\%) took at least one dose of opicapone (safety set) and 477 (94.3\%) patients had at least one post-baseline CGI-C assessment and were included in the full analysis set (Fig. 1). A total of 109 (21.5\%) patients prematurely terminated the trial and stopped treatment with opicapone; 84 patients $(17.0 \%)$ withdrew due to a TEAE (including $13.3 \%[n=66]$ due to an at least possibly related TEAE)

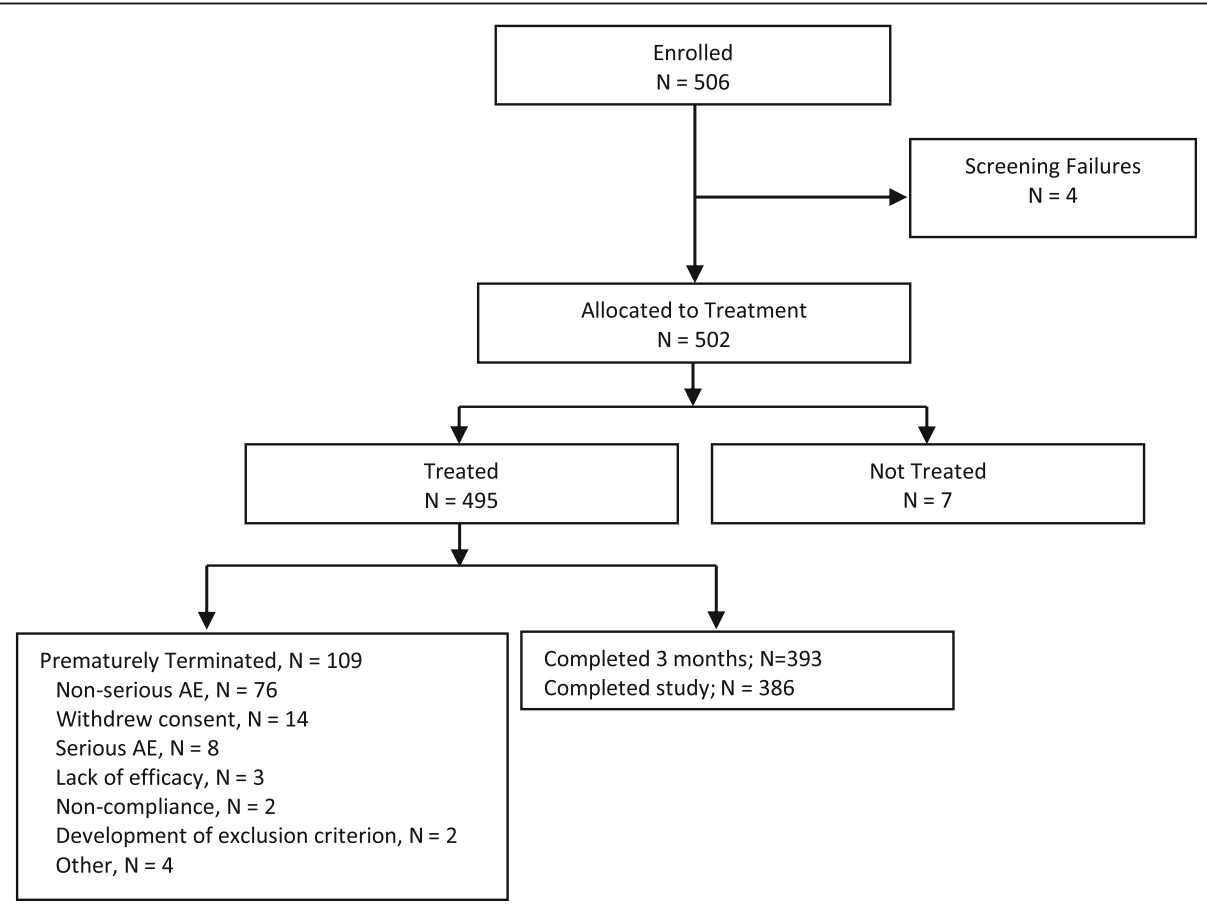

Fig. 1 Patient disposition 
while three $(0.6 \%)$ withdrew because of lack of efficacy. A high percentage of patients $(457 / 495 ; 92.3 \%)$ complied with $\geq 80 \%$ of doses. The mean \pm SD treatment compliance was $99.2 \pm 8.14 \%$. Of the 386 patients who completed the trial, 332 patients $(69.9 \%)$ continued to receive opicapone by prescription.

Baseline characteristics are provided in Table 1. The study population was comprised of white Caucasian patients with a mean \pm SD age of $67.7 \pm 8.98$ years, a mean \pm SD time since diagnosis of $102.1 \pm 59.6$ months and a mean $\pm S D$ duration of motor fluctuations of $30.1 \pm 38.0$ months. The majority of patients $(78.8 \%)$ were on another levodopa adjunct medication: the most common reported adjunct medications were rasagiline (27.5\%), pramipexole $(24.8 \%)$ and ropinirole $(22.4 \%)$.

\section{Clinician and patient global impressions of change}

After 3 months of treatment with opicapone $50 \mathrm{mg}$, the majority of patients (71.3\%) showed clinical improvement as judged by the investigators (CGI-C), with $43 \%$ reported as much or very much improved (Fig. 2a).

Similar improvements had already been observed at the earlier 1 month timepoint, where $75.8 \%$ of patients were judged as improved, $16.9 \%$ as having 'no change' and $6.6 \%$ as having worsened. For those UK patients $(n=95)$ who were also assessed at 6 months, $85.3 \%$ were judged as improved since commencing treatment (8.5\% very much improved and $49.4 \%$ much improved) while $8.5 \%$ were judged as showing 'no change' and $6.6 \%$ as having worsened. Patients self-rated levels of improvement (PGI-C) were consistent with primary results, with the majority of patients (76.9\%) reporting an improvement after 3 months of treatment with opicapone $50 \mathrm{mg}$ (Fig. 2b). For the subgroup of UK patients also assessed at 6 months $(n=94)$, $79.8 \%$ self-reported an improvement, $12.8 \%$ reported no change and $7.5 \%$ reported worsening.

Subgroup analyses for the primary efficacy endpoint (CGI-C at Month 3) confirmed that improvements were generally seen regardless of age or concomitant use of dopamine agonists with or without MAO-B inhibitors at baseline (Supplementary Table 1, Additional file 1).

\section{Presence of symptoms as assessed by the WOQ-9}

The proportions of patients reporting the overall presence of individual symptoms on the WOQ-9 decreased from baseline to 3 months (Fig. 3).

\section{Rating scale outcomes}

Assessments of UPDRS scores after 3 months of opicapone treatment showed stability of mentation, behavior and mood (Part I scores) and statistically significant improvements in activities of daily living (ADL, Part II) during OFF, motor scores (Part III) during ON and Total scores (Parts $\mathrm{II}+\mathrm{III}$ ) during $\mathrm{ON}$ (Table 2). After 3 months of treatment,
Table 1 Baseline characteristics (safety set)

\begin{tabular}{|c|c|}
\hline Category & $N=495$ \\
\hline Age (years); mean $\pm S D$ [range] & $67.7 \pm 8.98[43-87]$ \\
\hline \multicolumn{2}{|l|}{ Age categories; n (\%) } \\
\hline$\geq 30$ to $<65$ & $164(33.1)$ \\
\hline$\geq 65$ to $<85$ & $325(65.7)$ \\
\hline$\geq 85$ & $6(1.2)$ \\
\hline $\operatorname{Sex}(M / F) ; n(\%)^{a}$ & $315(63.6) / 179(36.2)$ \\
\hline \multicolumn{2}{|l|}{ Race: n (\%) } \\
\hline White & $495(100.0)$ \\
\hline \multicolumn{2}{|l|}{ Duration of Parkinson's disease (months); } \\
\hline Mean \pm SD & $102.1 \pm 59.60$ \\
\hline Median [range] & $89[5-420]$ \\
\hline \multicolumn{2}{|l|}{ Duration of motor fluctuations (months); } \\
\hline Mean \pm SD & $30.1 \pm 37.97$ \\
\hline Median [range] & $15[0-324]$ \\
\hline \multicolumn{2}{|l|}{ Symptoms (WOQ-9 assessment); n (\%) } \\
\hline Tremor & $299(62.7)$ \\
\hline Any slowness of movement & $459(96.2)$ \\
\hline Mood changes & $248(52.0)$ \\
\hline Any stiffness & $393(82.4)$ \\
\hline Pain/aching & $286(60.0)$ \\
\hline Reduced dexterity & $433(90.8)$ \\
\hline Cloudy mind/slowness of thinking & $223(46.8)$ \\
\hline Anxiety/panic attacks & $119(24.9)$ \\
\hline Muscle cramping & $288(60.4)$ \\
\hline Total levodopa daily dose $(\mathrm{mg})$; mean $\pm \mathrm{SD}$ & $580.1 \pm 289.1$ \\
\hline Median [range] & $525.0[100-3750]$ \\
\hline \multicolumn{2}{|l|}{ Adjunct therapies; $\mathrm{n}(\%)^{c}$} \\
\hline Rasagiline & $136(27.5)$ \\
\hline Pramipexole & $123(24.8)$ \\
\hline Ropinirole & $111(22.4)$ \\
\hline Amantadine & $105(21.2)$ \\
\hline Rotigotine & 68 (13.7) \\
\hline Safinamide & $67(13.5)$ \\
\hline Piribedil & $44(8.9)$ \\
\hline
\end{tabular}

${ }^{a} n=1$ missing, ${ }^{b}$ assessed in the full analysis set, ${ }^{c}$ patients could take $\geq 1$ adjunct therapy

there was a mean reduction of $0.8 \pm 1.9$ points in UPDRS IV scores (complications of therapy in the past week).

Improvements in both patient quality of life (as assessed by the PDQ-8) and non-motor symptoms (as assessed by the NMSS) were also observed after 3 months of treatment with opicapone. The mean \pm SD improvements of $-3.4 \pm 12.8$ points for PDQ- 8 and $-6.8 \pm 19.7$ points for NMSS were statistically significant versus baseline (both $p<0.0001$ ). For the NMSS, most 


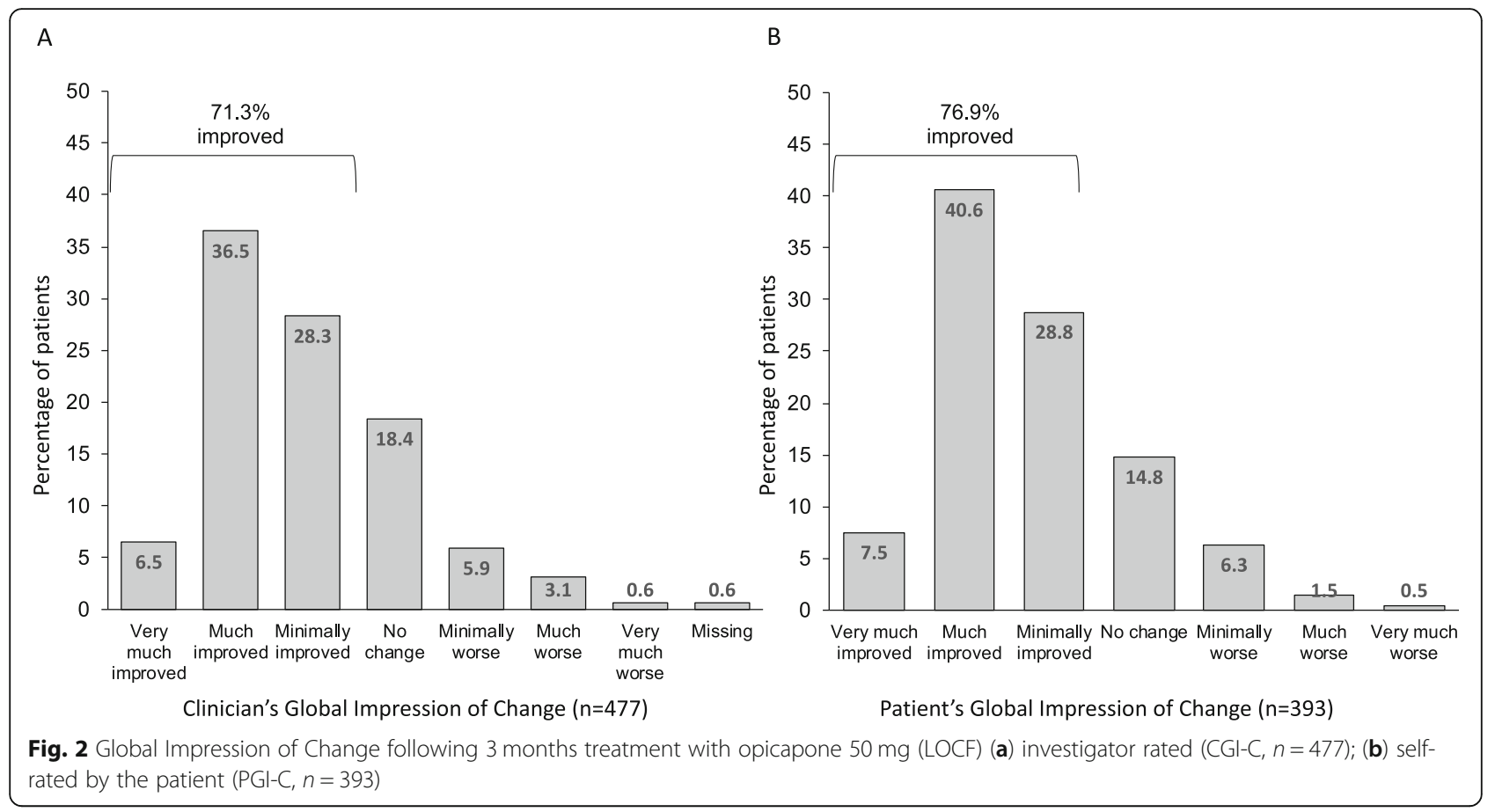

domains either remained stable or showed improvement versus baseline (Supplementary Table 2, Additional file 1). For example, sleep/fatigue showed a mean $\pm S D$ change from baseline of $-1.3 \pm 6.3$ points $(p<0.0001)$ and mood/cognition showed a mean $\pm \mathrm{SD}$ change from baseline of $-1.5 \pm 6.82$ points; $p<0.0001$ ).

\section{Levodopa dosing}

After 3 months of treatment with opicapone, most patients remained on the same total daily levodopa dose (85\% had no change in dose, $8.6 \%$ had a dose increase and $5.7 \%$ had a dose decrease) and levodopa dosing frequency $(77.1 \%$ had no change, $8.4 \%$ had an increase and

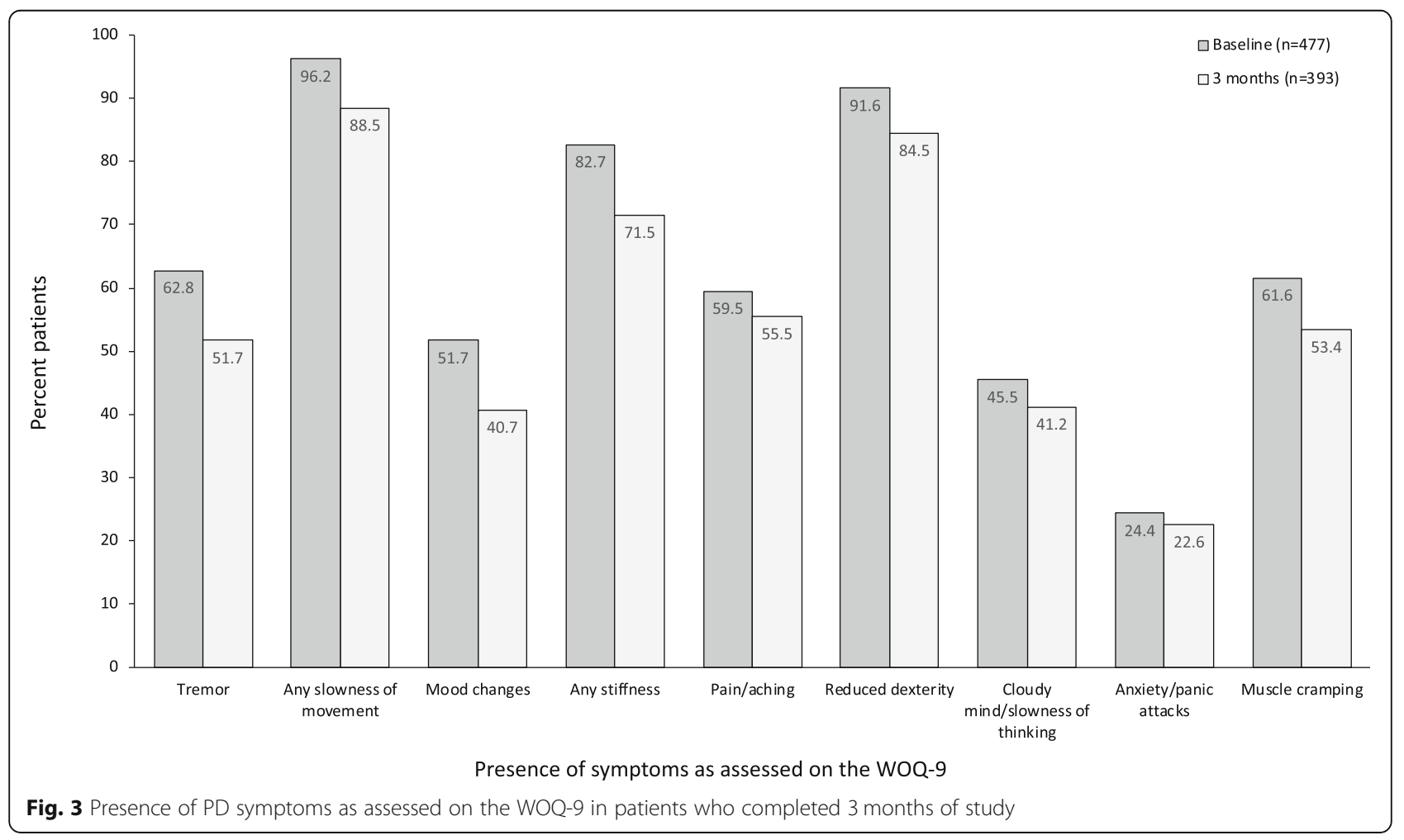


$12.0 \%$ had a decrease in dosing frequency [data missing for 2.4\%]), resulting in an overall mean change of approximately $-10 \mathrm{mg} /$ day. Similarly, for patients who reported dopaminergic adverse events (full analysis set), most patients $(62.7 \%)$ remained on the same total daily levodopa dose, $14.5 \%$ had a dose increase and $22.7 \%$ had a dose decrease, resulting in an overall mean change of $-26.6 \mathrm{mg} /$ day.

Table 2 Rating scale assessments

\begin{tabular}{|c|c|}
\hline \multicolumn{2}{|l|}{ Rating scale } \\
\hline \multicolumn{2}{|l|}{$\begin{array}{l}\text { UPDRS Part I (mentation, behavior } \\
\text { and mood); mean } \pm \text { SD }\end{array}$} \\
\hline Baseline $(n=477)$ & $2.3 \pm 2.1$ \\
\hline 3 months $(n=393)$ & $1.9 \pm 1.9$ \\
\hline Change from baseline $(n=393)$ & $-0.3 \pm 1.5$ \\
\hline \multicolumn{2}{|c|}{ UPDRS Part II (ADL during OFF); mean \pm SD } \\
\hline Baseline $(n=476)$ & $17.1 \pm 7.0$ \\
\hline 3 months $(n=391)$ & $13.9 \pm 6.8$ \\
\hline Change from baseline $(n=391)$ & $-3.0 \pm 4.6$ \\
\hline$P$ value vs. baseline & $<0.0001$ \\
\hline \multicolumn{2}{|c|}{$\begin{array}{l}\text { UPDRS Part III (motor scores during ON); } \\
\text { mean } \pm \text { SD }\end{array}$} \\
\hline Baseline $(n=477)$ & $26.5 \pm 12.1$ \\
\hline 3 months $(n=393)$ & $21.5 \pm 11.0$ \\
\hline Change from baseline $(n=393)$ & $-4.6 \pm 8.1$ \\
\hline$P$ value vs. baseline & $<0.0001$ \\
\hline \multicolumn{2}{|c|}{ UPDRS Total scores (Part II + III); mean \pm SD } \\
\hline Baseline $(n=477)$ & $37.5 \pm 16.9$ \\
\hline 3 months $(n=393)$ & $30.5 \pm 15.2$ \\
\hline Change from baseline $(n=393)$ & $-6.4 \pm 10.4$ \\
\hline$P$ value vs. baseline & $<0.0001$ \\
\hline \multicolumn{2}{|c|}{$\begin{array}{l}\text { UPDRS Part IV (complications of therapy); } \\
\text { mean } \pm \text { SD }\end{array}$} \\
\hline Baseline $(n=475)$ & $5.2 \pm 2.6$ \\
\hline 3 months $(n=391)$ & $4.2 \pm 2.4$ \\
\hline Change from baseline $(n=391)$ & $-0.8 \pm 1.9$ \\
\hline \multicolumn{2}{|l|}{ PDQ-8 Total Score; mean \pm SD } \\
\hline Baseline $(n=476)$ & $29.2 \pm 16.4$ \\
\hline 3 months $(n=393)$ & $25.2 \pm 15.8$ \\
\hline Change from baseline $(n=393)$ & $-3.4 \pm 12.8$ \\
\hline$P$ value vs. baseline & $<0.0001$ \\
\hline \multicolumn{2}{|l|}{ NMSS Score; mean \pm SD } \\
\hline Baseline $(n=477)$ & $44.6 \pm 30.3$ \\
\hline 3 months $(n=393)$ & $37.0 \pm 26.7$ \\
\hline Change from baseline $(n=393)$ & $-6.8 \pm 19.7$ \\
\hline$P$ value vs. baseline & $<0.0001$ \\
\hline
\end{tabular}

\section{Safety and tolerability}

Overall, 371 (74.9\%) patients experienced TEAEs, which were mostly assessed as mild or moderate (Table 3). Thirty four (6.9\%) patients experienced serious TEAEs, including one death due to endocarditis that was considered unrelated to treatment. A total of 223 (45.1\%) patients reported TEAEs that were assessed as at least possibly related to treatment. In line with the pivotal studies, the most frequent TEAEs $(>5 \%)$ considered possibly treatment-related were dyskinesia (11.5\%), dry mouth (6.5\%) and dizziness (4.8\%); diarrhea was reported in $3(0,6 \%)$ patients. The frequency of at least possibly related serious TEAEs was low: seven patients (1.4\%) had $\geq 1$ of these events - anxiety, visual hallucination, psychotic disorder, dizziness, hypertension, hypotension, tachycardia and femoral neck fracture.

TEAEs led to premature termination in $84(17.0 \%)$ patients, but the precipitating events were diverse: the most common TEAEs leading to withdrawal were nausea $(2.0 \%)$ and constipation (1.4\%). Of these, 66 patients (13.3\%) had at least possibly treatment-related TEAEs

Table 3 Incidence of treatment emergent adverse events

\begin{tabular}{|c|c|}
\hline TEAE Category & $N=495$ \\
\hline Any TEAE & $371(74.9)$ \\
\hline Any treatment-related ${ }^{a}$ TEAE & $223(45.1)$ \\
\hline Any serious TEAE & $34(6.9)$ \\
\hline 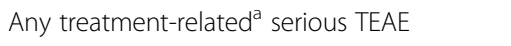 & $7(1.4)$ \\
\hline Any TEAE leading to discontinuation & $84(17.0)$ \\
\hline $\begin{array}{l}\text { Any treatment-related }{ }^{a} \text { TEAE leading to } \\
\text { discontinuation }\end{array}$ & $66(13.3)$ \\
\hline Any serious TEAE leading to discontinuation & $8(1.6)$ \\
\hline Any TEAE leading to death & $1(0.2)$ \\
\hline \multicolumn{2}{|l|}{ Treatment-related TEAEs ( $\geq 2 \%$ patients) } \\
\hline Dyskinesia & $57(11.5)$ \\
\hline Dry mouth & $32(6.5)$ \\
\hline Dizziness & $24(4.8)$ \\
\hline Nausea & $22(4.4)$ \\
\hline Constipation & $20(4.0)$ \\
\hline Insomnia & $12(2.4)$ \\
\hline Hallucination & $11(2.2)$ \\
\hline Fall & $10(2.0)$ \\
\hline \multicolumn{2}{|l|}{ TEAEs leading to discontinuation ( $\geq 1 \%$ patients) } \\
\hline Nausea & $10(2.0)$ \\
\hline Constipation & $7(1.4)$ \\
\hline Hallucination & $6(1.2)$ \\
\hline Dizziness & $5(1.0)$ \\
\hline Dyskinesia & $5(1.0)$ \\
\hline
\end{tabular}

${ }^{a}$ Treatment-related TEAEs were any TEAEs that were considered at least possibly related by the investigator and include the events with missing relationship assessment 
leading to discontinuation. There were no relevant changes in vital signs, physical and neurological examinations throughout the study.

When analyzed by age (above vs. below the baseline mean age), of the 371 patients that experienced TEAEs, $56.6 \%$ were from the older group ( $\geq 67.7$ years old). Patients older than 67.7 years old also accounted for the highest proportion of those who discontinued due to a TEAE $(n=57$ of 84$)$.

\section{Discussion}

Taken overall, the results of this large open-label study in PD patients with motor fluctuations are the first to confirm the effectiveness, safety and tolerability of once daily opicapone $50 \mathrm{mg}$ as used in routine clinical practice. The majority of patients showed improvements in their perception about global PD condition ( $\geq 70 \%$ as judged by clinicians and the patients themselves) 3 months after they started treatment with opicapone $50 \mathrm{mg}$. Treatment was generally well-tolerated and adverse events were as expected for a dopaminergic therapy in patients with PD.

While randomized controlled studies are often criticized as recruiting patients who might best meet study endpoints [27], this large study mirrored a clinical setting population by allowing the inclusion of a broader population of fluctuating PD patients, including patients with Hoehn and Yahr Stage IV. It is of interest to note that more patients were judged to have shown clinical improvement in this real life study than had been reported in the pivotal trials $(71.3 \%$ in this study vs. $59.6 \%$ in the combined pivotal studies [28]). Even more notable was the proportion of patients who were judged as much/very much improved (43.0\% in this study vs $25.2 \%$ in the combined pivotal studies [28]). These judgements made by the investigators were corroborated by the patients themselves with $40.5 \%$ patients reporting they were much or very much improved after 3 months treatment with opicapone $50 \mathrm{mg}$. Treatment with opicapone was also associated with a small but significant improvement in overall quality of life, as assessed using the PDQ-8. As also observed from the pivotal studies $[18,19]$, there was a proportion of patients who did not respond well to adjunct therapy with opicapone. Studies with entacapone have shown that the response to COMT inhibition is modulated by the COMT Val158Met polymorphism, with significantly enhanced efficacy in patients with the COMT (HH) genotype [29]. The impact of the COMT genotype on the opicapone response is unknown and merits further study.

Despite optimized anti-PD therapy (according to clinician's judgement) and the fact that most (78.8\%) patients were receiving levodopa plus another PD medication, UPDRS motor and ADL scores significantly improved (by 4.6 and 3.0 points, respectively) with opicapone as adjunct therapy. These magnitudes of effects have been reported to be clinically significant [30-32] and may therefore indicate that treatment with opicapone, not only increases $\mathrm{ON}$ time, but also improve the quality of ON time. Non-motor symptoms are now acknowledged as an important source of disability and contributor to worse quality of life for people living with PD [33, 34]. In line with prior pivotal studies with opicapone, this study also hinted towards an overall improvement in non-motor symptoms $[18,19]$. Some non-motor domains are known to correlate with the motor OFF-state and be dopa-responsive [35, 36] - with the implication that optimization of the pharmacokinetic and pharmacodynamic profile of levodopa with opicapone may be beneficial in their management. As recently suggested by Fabbri et al. [37], the effect of opicapone on various non-motor symptoms merits further investigation.

Patients in this study maintained their levodopa dose for up to 6 months with sustained benefits in symptomatic control. Similar observations have also been seen in the 1-yearlong extensions of the pivotal studies [28, 37, 38]. This hints at a possible long-term delay of need for levodopa increase.

Opicapone $50 \mathrm{mg}$ was generally well-tolerated, with the majority of events reported as mild or moderate in severity. While the most common reason for withdrawal from the study was adverse events (17.0\%), the causes were diverse, with the most frequent (nausea) affecting only $2 \%$ of patients $(n=10)$. While differences in study duration and settings make comparisons difficult, similar discontinuation rates due to AEs were reported in openlabel studies with entacapone $[39,40]$. Although dyskinesia was reported as a TEAE in $11.5 \%$ of patients, only five patients $(1 \%)$ discontinued from the study due to dyskinesia. The rate of serious TEAEs considered at least possibly related to treatment was low (1.4\%). One death was reported; the 69 year old male patient died due to severe endocarditis which was considered by the investigator not to be related to the study medication.

Strengths of this study lie in its size, broad inclusion criteria and routine practice setting. Although this study permitted inclusion of a broad range of disease severities (Hoehn and Yahr I-IV), we did not capture sufficient data in this pragmatic study to analyze by subgroups. Other weaknesses include those inherent to open-label studies without placebo control, where both the clinician and patient have expectations from treatment. Also, the study was only conducted in two countries (UK and Germany) and all patients were white Caucasian. We did not study OFF and ON time since patient diaries carry significant patient burden [41], which we wanted to minimize in this routine practice study.

\section{Conclusion}

In routine clinical practice, once-daily opicapone $50 \mathrm{mg}$ as adjunct to levodopa-treated PD patients with motor 
fluctuations significantly improved patients' perception about their global PD condition. A similar impression was reported by the clinicians. Opicapone was generally well tolerated and significantly improved quality of life and both motor and non-motor symptoms. These findings confirm the clinical utility of opicapone $50 \mathrm{mg}$ as an effective adjunct option for the management of motor fluctuations in levodopa-treated PD.

\section{Supplementary information}

Supplementary information accompanies this paper at https://doi.org/10. 1186/s40035-020-00187-1.

Additional file 1: Table S1. Subgroup analyses of the primary endpoint (CGl-C at Month 3) by age and concomitant use of other adjunct medications. Table S2. Change from baseline in NMSS domains.

\section{Abbreviations}

CGI-C: Clinician's Global Impression of Change; COMT: catechol-Omethyltransferase; MAO-B: Monoamine oxidase type B; NMSS: Non-motor Symptoms Scale; PD: Parkinson's disease; PDQ-8: Parkinson's Disease Questionnaire; PGI-C: Patient's Global Impression of Change; TEAEs: Treatment-emergent adverse events; UPDRS: Unified Parkinson's Disease Rating Scale; WOQ-9: Wearing-off Questionnaire (nine items)

\section{Acknowledgements}

We thank the study staff and patients involved in the trial. Medical writing support (literature searching, preparation of tables, styling of the manuscript) was provided by Dr. Anita Chadha-Patel (ACP Clinical Communications) funded by BIAL.

OPTIPARK Study Investigators group: Germany: Csaba Antal Zolnai, Claudius Bartels, Andreas Barth, Kriemhild Barth, Stephan Behrens, Arnfin Bergmann, Ralf Bodenschatz, Rommy Born,Moriz Brandt, Sebastian Brock, Bernd Brockmeier, Christof Brücke, Norbert Brüggemann, Bernhard Bühler, Uwe Bungard, Lukas Cepek, Ilona Csoti, Max Deist, Carl Detlev Reimers, Ulrich Dölle, Sylke Domke, Imanuel Dzialowski, Georg Ebersbach, Heike Eggert, Karla Eggert, Reinhard Ehret, Jana Engel, Urban Fietzek, Anke Friedrich, Michael Fritzinger, Florin Gandor, Klaus Gehring, Stephan Gierer, Stephanie Gierer, Vasil Gjaurov, Doreen Gruber, Özkan Günes, Thomas Haas, Kirsten Hahn, Anna Eszter Haraszti, Rolf Hartmann, Bernhard Haslinger, Eva Heiss, Heinz P. Herbst, Frank Hoffmann, Werner E. Hofmann, Günter Höglinger, Wolfgang Jost, Anna-Maria Kavcic, Christoph Kellinghaus, Bertold Klemperer, Fabian Klostermann, Thomas Knoll, Natalia Koleva-Alazeh, Jiri Koschel, Diana Waltraud Kraft-Safavi, Almut Kronenberger, Andrea Kühn, Andreas Kupsch, Thomas Lehnhoff, Peter Laumen, Paul Lingor, Karla Lippmann, Michael Lorrain, Fabian Maass, Siegfried Muhlack, Thomas Müller, Michael Nagel, Stephan Neudecker, Katja Odin, Christian Oehlwein, Hakan Orbasli, Wolfram von Pannwitz, Heidi Pape, Robert Pfister, Tino Prell, Reinhard Puzich, Daniela Rau, Rene Reese, Gerd Reifschneider, Gernot Reimann, Stefani Ries, Christoph Rieth, Charlotte Rewitzer, Ali Safavi, Alexander B. Schmied, Johannes Schwarz, Wolfgang Schwarz, Joachim Springub, Inga Suttrup Claus, Vera Tadic, Klaus TielWilck, Lars Tönges, Jens Tröger, Christoph Schrey, Alexander Schulze, Sven Thonke, Tobias Wächter, Achim S. Wannenmacher, Tobias Warnecke, Bettina Wieder, Martin Wimmer, Christian Winkler, Otto Witte, Dirk Woitalla, Samis Zella, Uwe Ziebold. UK: Jane Alty, Reem Amin, Michaela Boca, Stephen Butterworth, Camille Carroll, Gavin Charlesworth, K. Ray Chaudhuri, Rajkumar Chinnadurai, Jemima Collins, Jeremy Stephen Cosgrove, Samantha Cravey, Dinesh Damodaran, Nikolay Dimitrov, Rory Durcan, Simon Ellis, Adbdul Elmarimi, Jonathan Evans, James Fisher, Donald Grosset, Stuart Jamieson, Christopher Kobylecki, Sze Hway Lim, Veronica Lyell, Biju Mohamed, Sophie Molloy, Nicola Pavese, Dominic Paviour, Madeleine Purchas, Khalid Rashed, Christopher Rickards, Tabish Saifee, Gillian Sare, Christine Schofield, Naveen Setty, Jagdish Sharma, Ray Sheridan, Siew Lee Shu, Monty Silverdale, Rani Sophia, Sarah Statton, Malcolm Steiger, Christopher Thomas, Richard Walker, Tai Yen Foung.

\section{Authors' contributions}

$H R$ and AJL were study investigators, were involved in the study design, data collection, and data interpretation and contributed equally to the first draft. JFR, DM and PSS participated in the study design, data collection, data management, and data analysis. They provided critical review of the manuscript. All authors read and approved the final manuscript.

\section{Funding}

The study was funded by BIAL. Three authors (JFR, DM and PSS) were employed by the funder and participated in the study design, data collection, data management, and data analysis. The funder of the study had no other role in data interpretation or in the decision to submit the manuscript for publication. BIAL also supported reporting of study results by procuring medical writing support.

\section{Availability of data and materials}

The study sponsor (BIAL) undertakes to share, upon request, anonymized patient-level, study-level clinical trial data (analyzable data sets), and other information (such as protocols) from this clinical trial to qualified researchers as necessary for conducting legitimate research. Information is provided at www.bial.com.

\section{Ethics approval and consent to participate}

Institutional review boards at the participating sites approved the protocol and the trial was conducted in accordance with the Declaration of Helsinki and International Conference on Harmonization Good Clinical Practice Guidelines. All patients provided written informed consent.

\section{Consent for publication}

Not applicable.

\section{Competing interests}

HR reports acting on Advisory Boards, gave lectures and received research grants from Abbott, Abbvie, Bayer Health Care, BIAL, Boehringer/Ingelheim, Brittania, Cephalon, Desitin, GSK, Lundbeck, Medtronic, Merck-Serono, Novartis, Orion, Pfizer, TEVA, UCB Pharma, Valeant, and Zambon. AJL is funded by the Reta Lila Weston Institute of Neurological Studies, University College London, Institute of Neurology and reports consultancies from Britannia Pharmaceuticals and BIAL. He also reports grants and/or research support from the Frances and Renee Hock Fund and honoraria from Britannia Pharmaceuticals, Profile Pharma, UCB, Roche, BIAL, STADA, Nordiclnfu Care, and NeuroDerm. JFR, DM and PSS are employed by BIAL - Portela \& Ca, S.A.

\section{Author details}

${ }^{1}$ Department of Neurology, University of Dresden, Dresden, Germany. ${ }^{2}$ University College London, Reta Lila Weston Institute, London, UK. ${ }^{3} \mathrm{Global}$ Parkinson's Disease Department, BIAL - Portela \& CA S.A, Coronado, Portugal. ${ }^{4}$ Research and Development Department, BIAL - Portela \& CA S.A, da Siderurgia Nacional, 4745-457 S Mamede do Coronado, Portugal. ${ }^{5}$ Department of Pharmacology and Therapeutics, Faculty of Medicine, University Porto, Porto, Portugal. ${ }^{6}$ MedlnUP, Center for Drug Discovery and Innovative Medicines, University Porto, Porto, Portugal.

Received: 6 December 2019 Accepted: 17 February 2020

Published online: 04 March 2020

\section{References}

1. Appleman ER, Stavitsky K, Cronin-Golomb A. Relation of subjective quality of life to motor symptom profile in Parkinson's disease. Parkinsons Dis. 2011; 2011:472830.

2. Hechtner MC, Vogt T, Zollner Y, Schroder S, Sauer JB, Binder H, et al. Quality of life in Parkinson's disease patients with motor fluctuations and dyskinesias in five European countries. Parkinsonism Relat Disord. 2014;20: 969-74.

3. Cilia R, Akpalu A, Sarfo FS, Cham M, Amboni M, Cereda E, et al. The modern pre-levodopa era of Parkinson's disease: insights into motor complications from sub-Saharan Africa. Brain. 2014;137:2731-42.

4. Olanow CW, Kieburtz K, Rascol O, Poewe W, Schapira AH, Emre M, et al. Factors predictive of the development of levodopa-induced dyskinesia and wearing-off in Parkinson's disease. Mov Disord. 2013;28:1064-71. 
5. Chapuis S, Ouchchane L, Metz O, Gerbaud L, Durif F. Impact of the motor complications of Parkinson's disease on the quality of life. Mov Disord. 2005; 20:224-30

6. Stocchi F, Jenner P, Obeso JA. When do levodopa motor fluctuations first appear in Parkinson's disease? Eur Neurol. 2010;63:257-66.

7. Foundation MJF. Capturing and Elevating the Patient Voice. Available at https://www.michaeljfox.org/foundation/news-detail.php?capturing-andelevating-the-patient-voice. Last accessed January 2020.

8. Fox SH, Katzenschlager R, Lim SY, Barton B, de Bie RMA, Seppi K, et al. International Parkinson and movement disorder society evidence-based medicine review: update on treatments for the motor symptoms of Parkinson's disease. Mov Disord. 2018;33:1248-66.

9. NICE. Parkinson's disease in adults. Available at: nice.org.uk/guidance/ng71. Last accessed January 2020.

10. Pahwa R, Factor SA, Lyons KE, Ondo WG, Gronseth G, Bronte-Stewart H, et al. Practice parameter: treatment of Parkinson disease with motor fluctuations and dyskinesia (an evidence-based review). Report of the quality standards Subcommittee of the American Academy of neurology. Neurology. 2006;66:983-95.

11. Gordin A, Kaakkola S, Teravainen K. Position of COMT Inhibition in the Treatment of Parkinson's Disease. In: Gordin A, editor. Parkinson's Disease: Advances in Neurology, vol. 91. Philadelphia: Lippincott Williams \& Wilkins; 2003. p. 237-50

12. Schapira AH, Obeso JA, Olanow CW. The place of COMT inhibitors in the armamentarium of drugs for the treatment of Parkinson's disease. Neurology. 2000;55(11 Suppl 4):S65-8 discussion S9-71.

13. Poewe $W$. The role of COMT inhibition in the treatment of Parkinson's disease. Neurology. 2004;62(1 Suppl 1):S31-8.

14. Ferreira JJ, Katzenschlager R, Bloem BR, Bonuccelli U, Burn D, Deuschl G, et al. Summary of the recommendations of the EFNS/MDS-ES review on therapeutic management of Parkinson's disease. Eur J Neurol. 2013;20:5-15.

15. Riederer $\mathrm{P}$, Gerlach M, Muller T, Reichmann H. Relating mode of action to clinical practice: dopaminergic agents in Parkinson's disease. Parkinsonism Relat Disord. 2007;13:466-79.

16. Kiss LE, Soares-da-Silva P. Medicinal chemistry of catechol Omethyltransferase (COMT) inhibitors and their therapeutic utility. J Med Chem. 2014;57:8692-717

17. Rocha JF, Falcao A, Santos A, Pinto R, Lopes N, Nunes T, et al. Effect of opicapone and entacapone upon levodopa pharmacokinetics during three daily levodopa administrations. Eur J Clin Pharmacol. 2014;70:1059-71.

18. Ferreira JJ, Lees A, Rocha JF, Poewe W, Rascol O, Soares-da-Silva P, et al. Opicapone as an adjunct to levodopa in patients with Parkinson's disease and end-of-dose motor fluctuations: a randomised, double-blind, controlled trial. Lancet Neurol. 2016;15:154-65.

19. Lees AJ, Ferreira J, Rascol O, Poewe W, Rocha JF, McCrory M, et al. Opicapone as adjunct to levodopa therapy in patients with Parkinson disease and motor fluctuations: a randomized clinical trial. JAMA Neurol. 2017;74:197-206

20. FDA. Submitting Documents Using Real-World Data and Real-World Evidence to FDA for Drugs and Biologics Guidance for Industry. Available at https://www.fda.gov/regulatory-information/search-fda-guidancedocuments/submitting-documents-using-real-world-data-and-real-world evidence-fda-drugs-and-biologics-guidance. Last accessed January 2020.

21. Cave A, Kurz X, Arlett P. Real-world data for regulatory decision making: challenges and possible solutions for Europe. Clin Pharmacol Ther. 2019;106:36-9.

22. Hughes AJ, Daniel SE, Kilford L, Lees AJ. Accuracy of clinical diagnosis of idiopathic Parkinson's disease: a clinico-pathological study of 100 cases. J Neurol Neurosurg Psychiatry. 1992;55:181-4.

23. Stacy M, Hauser R, Oertel W, Schapira A, Sethi K, Stocchi F, et al. End-ofdose wearing off in Parkinson disease: a 9-question survey assessment. Clin Neuropharmacol. 2006;29:312-21.

24. Fahn S, Elton RL. Unified Parkinson's Disease Rating Scale. Recent developments in Parkinson's disease. 2: MacMillan Healthcare Information; 1987. p. 153-64

25. Jenkinson C, Fitzpatrick R, Peto V, Greenhalf R, Hyman N. The PDQ-8: development and validation of a short-form parkinson's disease questionnaire. Psychol Health. 1997;12:805-14.

26. Chaudhuri KR, Martinez-Martin P, Brown RG, Sethi K, Stocchi F, Odin P, et al. The metric properties of a novel non-motor symptoms scale for Parkinson's disease: results from an international pilot study. Mov Disord. 2007;22:1901-11.
27. Frieden TR. Evidence for health decision making - beyond randomized, Controlled Trials. N Engl J Med. 2017:377:465-75.

28. Ferreira JJ, Lees A, Rocha JF, Poewe W, Rascol O, Soares-da-Silva P. Longterm efficacy of opicapone in fluctuating Parkinson's disease patients: a pooled analysis of data from two phase 3 clinical trials and their open-label extensions. Eur J Neurol. 2019;26:953-60.

29. Corvol JC, Bonnet C, Charbonnier-Beaupel F, Bonnet AM, Fievet MH, Bellanger A, et al. The COMT Val158Met polymorphism affects the response to entacapone in Parkinson's disease: a randomized crossover clinical trial. Ann Neurol. 2011;69:111-8.

30. Shulman LM, Gruber-Baldini AL, Anderson KE, Fishman PS, Reich SG, Weiner WJ. The clinically important difference on the unified Parkinson's disease rating scale. Arch Neurol. 2010;67:64-70.

31. Hauser RA, Auinger P. Determination of minimal clinically important change in early and advanced Parkinson's disease. Mov Disord. 2011;26:813-8.

32. Hauser RA, Gordon MF, Mizuno Y, Poewe W, Barone P, Schapira AH, et al. Minimal clinically important difference in Parkinson's disease as assessed in pivotal trials of pramipexole extended release. Parkinsons Dis. 2014;2014 467131.

33. Chaudhuri KR, Schapira AH. Non-motor symptoms of Parkinson's disease: dopaminergic pathophysiology and treatment. Lancet Neurol. 2009:8:464-74.

34. Chaudhuri KR, Yates $L$, Martinez-Martin P. The non-motor symptom complex of Parkinson's disease: a comprehensive assessment is essential. Curr Neurol Neurosci Rep. 2005;5:275-83.

35. Franke C, Storch A. Nonmotor fluctuations in Parkinson's disease. Int Rev Neurobiol. 2017:134:947-71.

36. Storch A, Schneider CB, Wolz M, Sturwald Y, Nebe A, Odin P, et al. Nonmotor fluctuations in Parkinson disease: severity and correlation with motor complications. Neurology. 2013;80:800-9.

37. Fabbri M, Ferreira JJ, Lees A, Stocchi F, Poewe W, Tolosa E, et al. Opicapone for the treatment of Parkinson's disease: a review of a new licensed medicine. Mov Disord. 2018;33:1528-39.

38. Lees A, Ferreira JJ, Rocha JF, Rascol O, Poewe W, Soares-da-Silva PRI. Safety profile of Opicapone in the Management of Parkinson's disease. J Park Dis. 2019;9:733-40.

39. Larsen JP, Worm-Petersen J, Siden A, Gordin A, Reinikainen K, Leinonen M The tolerability and efficacy of entacapone over 3 years in patients with Parkinson's disease. Eur J Neurol. 2003;10:137-46.

40. Ahn TB, Im JH, Lee MC, Kim JW, Lee WY, Jeon BS. One-year open-label study of entacapone in patients with advanced Parkinson disease. J Clin Neurol. 2007;3:82-5

41. Papapetropoulos SS. Patient diaries as a clinical endpoint in Parkinson's disease clinical trials. CNS Neurosci Ther. 2012;18:380-7.

Ready to submit your research? Choose BMC and benefit from:

- fast, convenient online submission

- thorough peer review by experienced researchers in your field

- rapid publication on acceptance

- support for research data, including large and complex data types

- gold Open Access which fosters wider collaboration and increased citations

- maximum visibility for your research: over $100 \mathrm{M}$ website views per year

At $\mathrm{BMC}$, research is always in progress.

Learn more biomedcentral.com/submissions 